\title{
Hereditary Hyperbilirubinemia
}

National Cancer Institute

\section{Source}

National Cancer Institute. Hereditary Hyperbilirubinemia. NCI Thesaurus. Code C84761.

An inherited disorder affecting the metabolism of bilirubin. It results in increased levels of bilirubin in the blood. Representative examples of this condition include Gilbert syndrome and Crigler-Najjar syndrome. 